\title{
Competencias ciudadanas y propuesta para una escuela democrática por estudiantes del Colegio de Bachilleres del Estado de Sonora
}

\section{Citizenship competences and a proposal for a democratic school by students of Colegio de Bachilleres del Estado de Sonora}

Fecha de recepción:

30 Agosto del 2021

\author{
Mireya Berenice Yanez Diaz ${ }^{1}$ \\ y María Guadalupe González Lizárraga²
}

Fecha de aprobación: 03 Noviembre del 2021

1 Autora de correspondencia. Maestra de Horas Sueltas del Departamento de Lenguas Extranjeras, Universidad de Sonora. Correo: mireya.yanez@unison.mx ORCID: https://oooo-oooz-2756-4258

${ }^{2}$ Maestra de Tiempo Completo Titular, SNI 1 en el Departamento de Economía de la Universidad de Sonora. Correo: ma.guadalupe.gonzalez@unison.mx ORCID: https://oooo-ooo1-6716-7372

\section{Resumen}

El presente trabajo muestra los cuatro aspectos de las competencias ciudadanas: conocimientos, comportamientos, actitudes y valores de jóvenes estudiantes de educación media superior, y su propuesta de una escuela democrática. La indagación se delimitó a dos dimensiones que forman parte de la formación en ciudadanía: democracia y estado de derecho. Los datos se recabaron con una encuesta que respondieron 477 estudiantes que se encontraban cursando el último año de bachillerato en una institución pública del área urbana en Hermosillo, Sonora. De acuerdo con los resultados obtenidos los estudiantes poseen conocimiento sobre sus derechos, sus obligaciones y el concepto de democracia. Privilegian el respeto sobre otros valores y reportan pocas acciones de participación. Conforme a la narrativa escrita de los jóvenes, expresan que la institución educativa en la que se encuentran no cuenta con un ambiente democrático por lo cual proponen una mayor integración estudiantil en la toma de decisiones respecto a la forma de evaluación, la organización de la vida escolar y los temas de los cursos a participar. Con los resultados obtenidos se puede vislumbrar la generación de ciudadanos pasivos que reproducen un sistema jerárquico establecido que, si bien opinan, no se involucran de manera activa en propiciar cambios.

Palabrasclave: Educación, democracia, ciudadanía, competencias, educación media superior

\section{Abstract}

This article reports on the four aspects of citizenship competences: knowledge, behavior, values, and attitudes in a group of young high school students, and their proposal for a democratic school. Democracy and state of law were used as the two specific dimensions of citizenship. The data was gathered with a survey answered by 477 students enrolled in their senior year in a public school in the urban area of Hermosillo. According to the results, the students have a working knowledge about their rights, obligations, and the concept of democracy. They privilege respect above other values and report few chances to participate at school. Based on their written narrative, the school doesn't have a democratic environment hence they propose to integrate students in the decision-making process on regards to evaluation criteria, school life and topics of courses they can take part in. Thus, the results let us infer that the new generation of citizens is passive and reproduces an established structural system in which they can sometimes express their opinion but cannot participate actively in its changes.

Keywords: Education, democracy, citizenship, competencies, high school education

Código JEL: I2, K36, I21, I28

\section{Introducción}

Una delas preocupaciones continuas del ser humano, desde los orígenes de las sociedades modernas, 
ha sido la formación de ciudadanía, vigente en nuestros días bajo un enfoque del derecho, en pro de la democracia, y el fomento de una cultura para la paz (UNESCO, 2015 y 2021).

El Estado Mexicano ha incluido en los planes y programas de estudio elementos para este tipo de formación en los niveles educativos desde preescolar hasta la educación media superior, intentando dar respuesta a exigencias marcadas por organismos internacionales a través de los objetivos para el Desarrollo Sostenible incluidos en la Agenda 2030. Sin embargo, los conocimientos incorporados en los planes de estudio poco analizan de la realidad en la que se vive en las escuelas y las comunidades inmediatas de las personas, esto es, las políticas en materia de ciudadanía quedan en principios $\mathrm{y}$ valores morales que poco se practican en las escuelas y medio en donde se desenvuelven los y las estudiantes.

En este contexto nacional, cada año cerca de $5 \%$ de la población mexicana llega a la mayoría de edad, conforme lo dicta la Constitución Política de los Estados Unidos Mexicanos (Diputados, 2021), de ellos el 8o\% ingresa a la educación media superior. De manera deseable deberán conocer la lógica con la que operan las reglas formales de interacción social para convivir, opinar y participar en las decisiones que el gobierno toma para mantener o mejorar la vida en sociedad. Aunado a ello, participarán en la elección para cambiar o mantener algún tipo de gobernantes de su ciudad, de su estado y del país, para fomentar la democracia participativa, la cultura de paz y la promoción y cumplimiento del estado de derecho.

Al mismo tiempo, la experiencia de cursar la preparatoria permite desarrollar habilidades y conocimientos, el progreso social individual, familiar e incluso comunitario, en este sentido, este nivel de estudios se convierte un espacio de madurez emocional, cognitiva y social, en donde se adquieren responsabilidades y se configuran las personas como sujetos reflexivos (Weiss, Guerra, Hernández, Grijalva, \& Avalos, 2008).

La juventud, es la mejor forma de impulsar cambios en la sociedad; son ellos y ellas requieren fortalecer, reorientar y re-significar sus conocimientos, valores, actitudes y acciones en pro del impulso de la democracia. Este rol como agente activo se puede redefinir al modificar la relación que guarda con la esfera política y la sociedad (Giroux, 1993). El tener datos sobre esta población permite diseñar programas en educación superior para fomentar una ciudadanía democrática participativa e incluso atender con programar de educación no formal a aquellos ciudadanos noveles que no continuaron con sus estudios, e impulsar políticas publicas orientadas a la juventud.

Con base en lo anterior, se planteó como objetivo el conocer las competencias ciudadanas de jóvenes estudiantes de bachillerato general en Hermosillo. Con el fin de conocer las habilidades con que los jóvenes hacen frente a las exigencias de su estatus de ciudadano. Por lo tanto, esta publicación busca dar a conocer y discutir los hallazgos sobre las competencias ciudadanas desarrolladas por los preciudadanos y dar voz a los jóvenes al compartir las propuestas para una escuela democrática de una muestra del estudiantado del Colegio de Bachilleres del Estado de Sonora, en Hermosillo, Sonora, México.

\section{Desarrollo Conceptual de la Investigación}

Ciudadanía es una palabra con múltiples acepciones que se ha utilizado como una estrategia para solucionar múltiples problemáticas sociales (Aragón, 2015). En esta investigación se concibe como una construcción social de identidad personal enmarcada en un contexto sociopolítico que, como tal, se vincula a una forma de vida democrática, que implica los ámbitos personales-familiares; y recoge las experiencias de los sujetos, el reconocimiento de los derechos humanos, y la lucha de nuevos espacios como sujetos con poder político en diversas esferas sociales. Para formar a los ciudadanos se utiliza la educación basada en competencias; para este enfoque educativo, las competencias ciudadanas se entienden como conocimientos, comportamientos, actitudes y valores (Marco, 2003), elementos que se conjugan en la formación de ciudadanía como modelo pedagógico utilizado en las escuelas mexicanas (Fernández, 2013).En consecuencia, se reconoce que, de manera formal, desde la escuela, los sujetos se formen como ciudadanos bajo la promoción del conocimiento de los derechos humanos fundamentales, la representatividad como parte del ejercicio participativo, y las actitudes con base a valores establecidos en las diversas esferas 
sociales en las que confluyen las personas (Aragón, 2015; Heater, 2007; Mejía \& Perafán, 2006), los que se vienen a reforzar o contraponer, con los valores impulsados por la familia, la sociedad y los medios.

La revisión de estudios antecedentes arroja que las investigaciones sobre competencias ciudadanas varían en aproximaciones, metodologías e incluso temáticas a desarrollar dentro de distintas asignaturas. Destacan aquellos que se han realizado a nivel de un país, como es el caso de Colombia, España, y Argentina (Astiz, 2007; Ruiz \& Chaux, 2005; Marco, 2003). En México, los estudios más amplios localizados corresponden a investigaciones desarrolladas por instituciones gubernamentales (INE, 2016; IFE, 2013). Hay estudios que buscan profundizar en aspectos específicos dentro de las competencias ciudadanas, por ejemplo, conocimiento político (Saldierna, Muñiz, \& Marañón, 2017), participación política por medio del sufragio (Gómez, Tejera, Aguilar, Ramírez \& Díaz, 2012); o de la ciudadanía como tema general. Se toma como referente que en educación media superior el currículo establece desarrollar ciudadanos para una sociedad democrática (DGB, 2017); se destaca la participación, el desarrollo de una conciencia cívica y ética, el reconocer y respetar el Estado de Derecho, y como actitud se prioriza el respeto. Los estudios revisados se delimitaron a dos dimensiones temáticas: democracia y estado de derecho.

\subsection{Democracia}

El termino democracia se refiere a un sistema y régimen político que requiere una forma de vida, convivencia pacífica y de comunicación asertiva, que utiliza una serie de procedimientos e instituciones como herramientas para reconocer la esencia del individuo y del colectivo, controlar el poder, exigir y resguardar derechos, e integrar a la sociedad en una comunidad con conciencia cultural e histórica, la cual puede oponerse al concepto de derechos universales (Sartori, 2012; Touraine, 2000). Si el ciudadano actúa de manera activa, se involucra en la conformación de la democracia y el cumplimiento de obligaciones, si no, la democracia se puede ver reducida a un sistema de organización política donde una minoría tiene poder sobre la mayoría.

De acuerdo con Salazar y Woldenberg (2020) los principios que rigen la democracia en México son: a) la soberanía popular, modo de organizar el poder político donde el pueblo es el objeto y el sujeto del gobierno; b) la mayoría y la defensa de los derechos de las minorías, a través de mecanismos de elección, como el sufragio, se eligen gobernantes que representan a la mayoría, pero para legitimarse democráticamente tienen que incluir los derechos y la participación de minorías; y c) representación política democrática, los representantes elegidos por el pueblo son responsables de tomar las decisiones políticas o bien, se puede recurrir a un plebiscito si se desea la opinión directa de la ciudadanía.

Toro (200o) menciona que otros principios de la democracia son la secularidad, es un orden social construido; la autofundación, tiene leyes y normas determinadas por la sociedad y para la sociedad que coadyuvan a vivir, cumplir y proteger; la incertidumbre, no hay un solo modelo ideal, lo tienen que determinar los ciudadanos de cada Estado; la ética, se tiene que buscar el preservar y fortalecer la dignidad humana a través de los derechos; la complejidad, incluye todos los intereses; y lo público, se construye desde la sociedad. A su vez, la democracia está contenida en valores entendidos como normas que debe compartir toda la población e instituciones (Salazar \& Woldenberg, 2020; Sartori, 2012; Touraine, 2000). Los tres valores sobre los que reposa la democracia en México son la libertad, la igualdad y la fraternidad (Salazar \& Woldenberg, 2020).

Un eje fundamental para la construcción de una nación democrática le corresponde a la escuela, ya que es responsabilidad de ésta formar a quienes serán ciudadanos y prepararlos para participar activamente en las decisiones que atañen a toda la sociedad. La incorporación a la escuela supone una integración institucional, lo cual significa la adaptación a una amplia cultura normativa, a través de conocimientos de reglas (que son obligatorias para la comunidad escolar), y el estudiantado las interioriza a través de actitudes que asumen y finalmente, ellos y ellas las utilizarán en acciones específicas que les permiten sobrevivir en el medio escolar (Bolívar, 2016).

Este proceso de integración representa un ejercicio de participación en las decisiones y acciones colectivas que repercuten en la formación ciudadana (Taddei, 2019). Esta preparación deberá dirigirse a dotar al estudiantado de conocimientos que les permitan entender mejor su entorno, pero también es necesario impulsar una visión crítica y reflexiva, así como la participación de las y los estudiantes en la toma de decisiones. 
La participación es el concepto que de manera sintética indica una forma de ser y de actuar en consecuencia de las diversas formas de pensar, y concebir el mundo. En este proceso formativo, los medios de comunicación y las redes sociales digitales juegan un papel fundamental en el contenido y las formas de acercar la información a la juventud con la que construyen una manera de pensar, pero sobre todo de actuar, o permanecer pasivos. Entre las investigaciones llevadas a cabo en la línea de adolescentes-jóvenes y democracia destacan la de Caro, Pivatto, Quinteros, Sema y Torrejón (2012) quienes mencionan que el nivel de conocimiento que los jóvenes tienen sobre la democracia afecta directamente en su participación, así mismo, la apatía y desafección que los jóvenes tienen hacia los temas de política han sido abordados por Ávila y Díaz (2017), Gómez, Tejera, Aguilar, Ramírez y Díaz (2012), Olivera (2009), Saldierna, Marañón y Muñiz (2015), e instituciones como el IFE (2013), el IMJUVE (2012) y el INE (2016).

En este sentido, la juventud se encuentra inmersa y en constante tensión con diversos fenómenos sociopolíticos lo cual coadyuva a construir y reconstruir sus acepciones de democracia y de ciudadanía. La educación, sobre todo los programas educativos formales, son un recurso con el cual cuenta el Estado para contrarrestar los influjos socioculturales negativos y la influencia del capitalismo, y desarrollar un modelo ideal de ciudadano y de democracia. En este sentido, se cuenta con programas de educación establecidos formalmente y que sirven de base para la enseñanza en el sector público desde preescolar hasta nivel medio superior, éstos logran un cierto nivel de impacto, debido al contexto en donde los individuos se están desarrollando.

\subsection{Estado de derecho y cultura de la legalidad}

El estado de derecho, en un sentido muy simple, se puede referir a las leyes y reglas que engloban los distintos derechos que pretenden mantener el orden; mientras que la cultura de la legalidad se enfoca en el conocimiento que tienen los ciudadanos de sus derechos, los esfuerzos que realizan por acatar las normas o leyes que los rigen, los efectos concretos que el ejercicio o la falta de puede tener en la sociedad (Laveaga, 200o). El autor sostiene que en el estado de derecho y por consiguiente la cultura de la legalidad queda inmersa la necesidad de que el sujeto conozca y comprenda la construcción del sistema político del país donde reside junto a las instituciones gubernamentales, las estructuras de poder y jerarquías que conforman al Estado. En un aspecto más amplio, esto también incluye las funciones de cada institución, y del Estado mismo, y conocer la integración socioeconómica, ética y social.

Dado el estatus de algunos de los sujetos de estudio como pre-ciudadanos, tienen acceso limitado a instancias gubernamentales lo cual no los exime de conocer las funciones de distintas organizaciones y los medios en que pueden incidir en éstas. Por ejemplo, solicitar asesoría y en caso, iniciar un proceso en la Procuraduría de la Defensa del Menor y la Familia. En cambio, están amparados bajo la Ley General de los Derechos de Niñas, Niños y Adolescentes que establece que tienen derecho: a la vida, a la supervivencia, y al desarrollo; de prioridad; a la identidad; a vivir en familia; a la igualdad sustantiva; a no ser discriminado; a vivir en condiciones de bienestar y a un sano desarrollo integral; a una vida libre de violencia y a la seguridad social; a la inclusión de niñas, niños y adolescentes con discapacidad; a la educación; al descanso y al esparcimiento; a la libertad de convicciones éticas, pensamiento, conciencia, religión y cultura; a la libertad de expresión y de acceso a la información; de participación; de asociación y reunión; a la intimidad; a la seguridad jurídica yal debido proceso; migrar; y acceso a las tecnologías de la información y comunicación, así como a los servicios de radiodifusión y telecomunicaciones, incluido el de banda ancha e Internet (SEGOB, 2014). El derecho a la educación también se encuentra en el artículo tercero de la Constitución Política Mexicana, y se extiende hasta después de la mayoría de edad como el acceso a la educación superior a cargo de cada estado.

Otros derechos que permiten acceder a un estado de bienestar (Aragón, 2015), y por consiguiente es necesario que los ciudadanos los conozcan son el derecho al trabajo, la educación y la salud (Marshall, 1950). El artículo 123 de la Constitución Política de los Estados Unidos Mexicanos menciona que el derecho de toda persona a trabajar de manera digna y socialmente útil; y otros aspectos están contenidos en la Ley Federal del Trabajo. Mientras que el artículo 4to constitucional establece la protección a la salud. 
Cuando ciudadanos de pleno derecho, Cortina (1997) plantea que es necesario ejercer la ciudadanía al formar parte de la opinión pública, informarse y dialogar. Si el diálogo falla, que estén al tanto de otros mecanismos como organizaciones civiles, que pueden influir, afectar o persuadir la toma de decisiones de instituciones gubernamentales, es por medio de la incidencia (Canto, 2002); y que conozcan sobre las diversas instancias en las que pueden reclamar las garantías de sus derechos, y los de los demás (Aragón, 2015). De los estudios sobre cultura de la legalidad realizados en el país destaca el de Arango, Leyva, Marañón, y Lozano (2017) realizado en Monterrey, Nuevo León donde se indagó sobre los cultura y conocimientos de la legalidad y participación ciudadana, y encontraron que hay un conocimiento "aprobatorio" hacia el estado de derecho y la justicia, pero un bajo involucramiento e interés hacia la vida comunitaria y los asuntos sociales públicos.

\subsection{Valores}

El sistema educativo mexicano ha utilizado diferentes tipos de valores en distintas etapas educativas, pasando de los de carácter ético, los religiosos, los morales, los humanos y los políticos en distinto momento (Latapí, 2003). En tanto que la formación en ciudadanía se inclina a desarrollar los valores humanos, en especial los contenidos en la Declaración Universal de Derechos Humanos (UNESCO, 1948), los cuales siguen siendo relevantes y vigentes para nuestro momento socio histórico ya que no se han consolidado como prácticas comunes ni como legislaciones en varios países. En México, el artículo tercero o del Derecho a la Educación menciona la libertad, la justicia y el respeto; mientras que, desde un punto de vista político, el INE (Salazar \&Woldenberg, 2020), con base en el artículo 1 de la DUDH, destaca como valores de la democracia: libertad, igualdad y fraternidad.

El valor libertad, mencionado tanto en lo educativo como en lo democrático, tiene dos acepciones; la primera, es la capacidad de autorregularse, y la segunda se refiere al actuar sin intervención de otro individuo, organismo u organización dentro de lo permitido por la ley, apegándose al estado de derecho de manera responsable, sin que se arriesgue la soberanía popular (Salazar \&Woldenberg, 2020; Touraine, 200o). En tanto que la igualdad se refiere a que todos los ciudadanos tienen los mismos derechos y obligaciones ante la ley, no hay diferencia en términos políticos ni de estratos sociales (Salazar \&Woldenberg, 2020). Los mismos autores mencionan que el valor fraternidad se asocia a un comportamiento o convivencia entre los ciudadanos donde exista la cooperación ante conflictos, que las diferencias y contradicciones se resuelvan de manera pacifica y legal, en caso de ser necesario, que sean tolerantes y acepten las diferencias de los otros.

El trascender de los valores en el sistema educativo fue analizado por Latapí (2003), quien menciona que es un reto formar en valores, desde el delimitarlos, definirlos, conocer la etimología a lograr que los estudiantes vivan los valores. Al respecto, Moreno y Peniche (2020), mencionan que el formar en valores es un reto para el docente de Bachillerato ya que cuenta con un contexto adverso, pero que se puede lograr si se trabaja en conjunto con los padres y la sociedad, y enfatizan en la necesidad de fomentar el valor de la solidaridad.

Si bien, a pesar de que existen sustentos teóricos que nos permiten definir distintos valores, estos son constructos abstractos que se establecen social y culturalmente, y que a la vez denotan intereses del individuo (Garay et al, 2008), por lo cual pueden variar conforme a cada estudiante lo haya interiorizado y lo ponga en práctica. De manera similar, la delimitación de estos, dado al principio de autonomía curricular, dependerá de los diseñadores de los programas base y posteriormente de quienes perfilen los materiales que se pongan a disposición de los estudiantes, sean estos módulos de aprendizaje o libros de texto.

\section{Diseño metodológico de la investigación}

El estudio se estructuró con base en la propuesta de investigación educativa evaluación basada en estándares de Stake (2004). Con la finalidad de conocer la integración de las competencias ciudadanas en los programas de bachillerato general, se desarrolló un análisis de contenido superficial o manifiesto del currículo, partiendo de los programas base (DGB, 2017) hasta los módulos de aprendizaje del Colegio de Bachilleres del Estado de Sonora. Con lo resultados obtenidos y diversos aportes teóricos se delimitaron los conocimientos, actitudes y valores, y las acciones que se enmarcan en la dimensión de democracia y del estado de derecho (Tabla 1). 
Tabla 1. Competencias ciudadanas y los cuatros aspectos que la componen

\begin{tabular}{|c|c|c|c|c|}
\hline $\begin{array}{c}\text { Aspecto de } \\
\text { competencia / } \\
\text { Dimensión }\end{array}$ & Conocimiento & Comportamiento & Actitudes & Valores \\
\hline Democracia & $\begin{array}{c}\text { Definición } \\
\text { División de poderes } \\
\text { Principios } \\
\text { Deberes ciudadanos }\end{array}$ & Participación & $\begin{array}{c}\text { Percepción de la } \\
\text { democracia en el país }\end{array}$ & \\
\hline $\begin{array}{l}\text { Estado de } \\
\text { derecho }\end{array}$ & $\begin{array}{c}\text { Ley general de niñas, niños } \\
\text { y adolescentes } \\
\text { Derecho a la educación } \\
\text { Derecho a la salud } \\
\text { Derecho al trabajo }\end{array}$ & $\begin{array}{l}\text { Cultura de la } \\
\text { legalidad }\end{array}$ & $\begin{array}{l}\text { Aceptación hacia } \\
\text { actividades ilegales }\end{array}$ & Escala de valores \\
\hline
\end{tabular}

Con base en la distribución anterior, se construyó el instrumento: un cuestionario, diseñado para esta investigación. Éste consta de 45 preguntas divididas en cuatro secciones: la primera sección es sobre conocimientos, la segunda sobre comportamiento, la tercera sobre actitudes y valores, y la cuarta recaba información sobre el nivel socioeconómico (AMAI, 2018). Cada una de las secciones, a su vez, contienen preguntas que se relacionan con democracia y estado de derecho. El instrumento se sometió a dos pruebas piloto en instituciones del mismo subsistema de bachillerato y con población similar en tanto características de sexo, edad, y nivel socioeconómico. El análisis de fiabilidad para todas las preguntas del instrumento arroja un Alfa de Cronbach de 0.875 y un Alfa de Cronbach basada en elementos estandarizados de 0.878 .

La recolección de datos se llevó a cabo durante el mes de octubre del 2019, dentro de las aulas de clase del Colegio de Bachilleres del Estado de Sonora, plantel Villa de Seris en horario de clase. Dicha institución cuenta con la certificación vigente del Padrón de Calidad del Sistema Nacional de Educación Media Superior (COPEEMS, 2019), lo cual significa que la escuela aplica los programas vigentes a nivel federal, cuenta con el personal preparado y con las instalaciones propicias para promover un ambiente de aprendizaje adecuado.

Se seleccionó a estudiantes que se encontraban cursando el quinto semestre, tomando en cuenta que los jóvenes han cursado la mayoría de las materias vinculadas al eje para la formación ciudadana. De un universo de 541 alumnos inscritos en ambos turnos, matutino y vespertino, se recopilaron 477 cuestionarios. De los participantes en el estudio, $51.6 \%$ son mujeres y $48.4 \%$ son hombres. Los encuestados reportaron tener entre 16 y 19 años, concentrándose el mayor porcentaje en los 17 años $(76.2 \%)$. Casi la mitad de la muestra pertenece a un nivel socioeconómico alto $(43.8 \%)$, es decir que los jefes de familia cuentan con estudios profesionales de licenciatura o posgrado, tiene acceso fijo a Internet en casa, y en sus familias se invierte una parte del ingreso en educación; en menor porcentaje se encuentra el nivel medio-alto (28.9\%) y el medio $(15.9 \%)$, en estos hogares también tienen acceso a Internet e invierten, pero en menor proporción, en la educación de los hijos, de acuerdo a los criterios establecidos por la AMAI (2018). En todo momento se conservó el anonimato respecto a nombres y otros posibles datos de identificación de los informantes, siendo la participación voluntaria.

Los datos recabados fueron capturados en el programa estadístico SPSS de los cuales se realizaron análisis de frecuencias y medidas de tendencia central. Los resultados obtenidos de las preguntas abiertas fueron exportados y se llevó a cabo el análisis cualitativo y cuantitativo del discurso a partir del cual se elaboraron categorías analíticas primarias y secundarias.

\section{Análisis de los resultados obtenidos}

\subsection{Democracia}

Con la finalidad de indagar la manera en que los jóvenes definen la democracia, se les solicitó escribir el concepto de democracia. En un primer nivel de análisis se categorizaron cinco conceptos que adquieren relevancia de acuerdo con el número de apariciones en las respuestas, de mayor a menor: forma, sistema, poder, derecho, y proceso. En un segundo nivel, se asociaron los conceptos con otros elementos semánticos. Estas asociaciones denotan 
algunos rasgos de democracia mencionados por Sartori (2012) como son la racionalidad, la libertad política y la diversidad. A la vez, concuerdan con los principios de la democracia en México (Salazar \& Woldenberg, 2020) donde se mencionan la soberanía popular, los mecanismos de elección y la representación política. En la Figura 1 se puede observar las relaciones asociativas de cada concepto.

De los discursos se retoman dos escritos de estudiantes que aun cuando no se relacionan con ninguno de los conceptos categorizados, expresan de forma contundente un sentir: "es algo que nos hace participar a todos", opina el participante 506241; mientras que el participante 502223 menciona que es "algo que nos divide".

También destacan agentes involucrados en la toma de decisiones, encontrando de mayor a menor (de acuerdo con el número de menciones), cuatro categorías: todos (para designar una mayor participación de personas), pueblo (elegir, dar voz y poder), personas, y mayoría. Esto refleja que en el constructo de democracia de los jóvenes la comunidad se coloca como un interés colectivo sobre lo individual, de acuerdo con definiciones revisadas en Touraine (2000).

Se les solicitó a los estudiantes que escribieran los tres poderes de la unión, de las 305 respuestas escritas, 236 corresponden a la respuesta correcta en distinto orden: Ejecutivo, Legislativo y Judicial, lo que corresponde a $49 \%$ de respuestas correctas. En otra de las preguntas abiertas se les solicitó a los estudiantes que escribieran tres principios de la democracia, en orden de mayor a menor menciones respondieron: justicia, igualdad, libertad, respeto, votación, honestidad, equidad, participación, transparencia, solidaridad y elección. Los porcentajes correspondientes se pueden visualizar en la Figura 2.

De los deberes ciudadanos incluidos en la carta magna los participantes identificaron el inscribirse en el padrón electoral, en su mayoría, (96.5\%), seguido de el votar en las elecciones y consultas populares $(85.9 \%)$, realizarelserviciomilitar $(62.3 \%)$, e inscribirse en el catastro de la municipalidad (58.2\%). Mientras que menos de un tercio señaló el desempeñar cargos de elección popular de la Federación o del Estado (29.1 \%); el que la mayoría de los informantes no identificara desempeñar este deber indica un énfasis en los derechos, pero dejando de lado las responsabilidades y/u obligaciones que el ciudadano tiene de desempeñar cargos públicos e involucrarse en asuntos políticos, situación que puede causar desbalance y la promoción de una ciudadanía pasiva (Aragón, 2015; Heater, 2007).

El tipo de participación por el que optan los jóvenes incluye en primer lugar, firmar peticiones, juntar firmas, o enviar un escrito a alguna autoridad (60.5\%); en segundo, solicitar el apoyo de tutor o algún representante (58.5\%); y en tercero, recabar

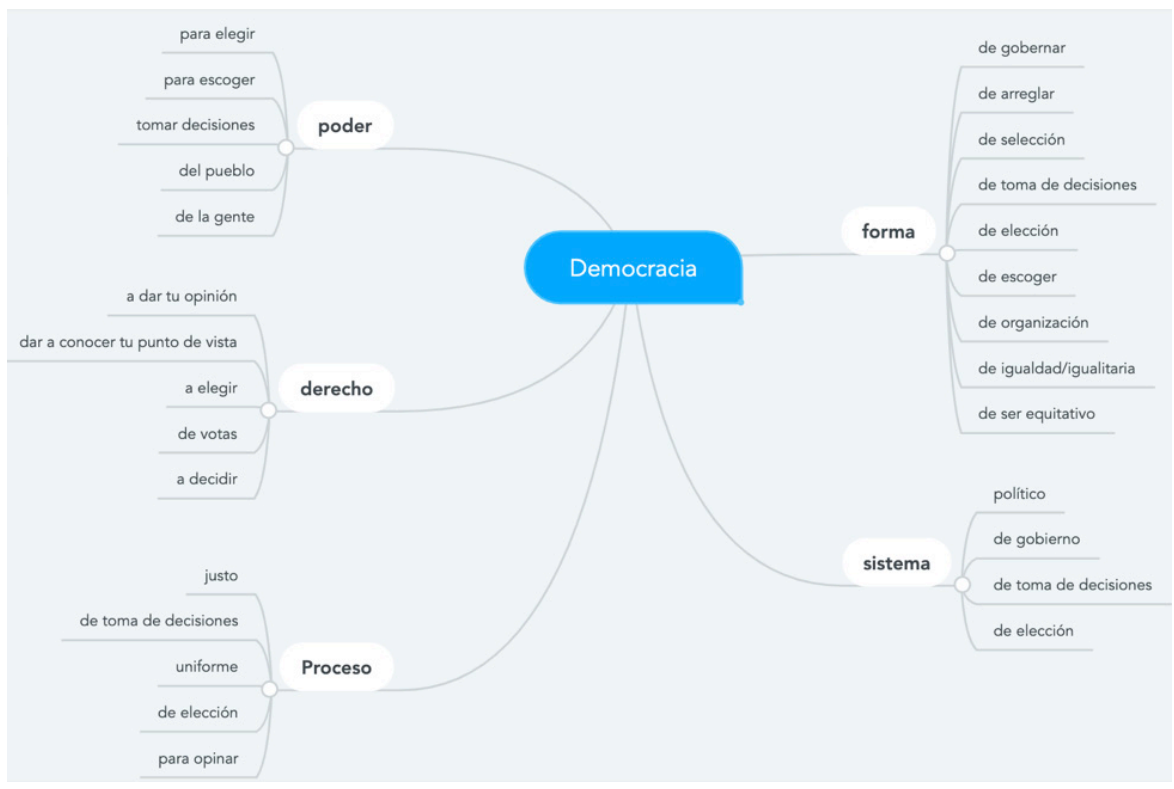

Figura 1. Diagrama que muestra los términos relacionados con democracia.

Fuente: Elaboración propia. 


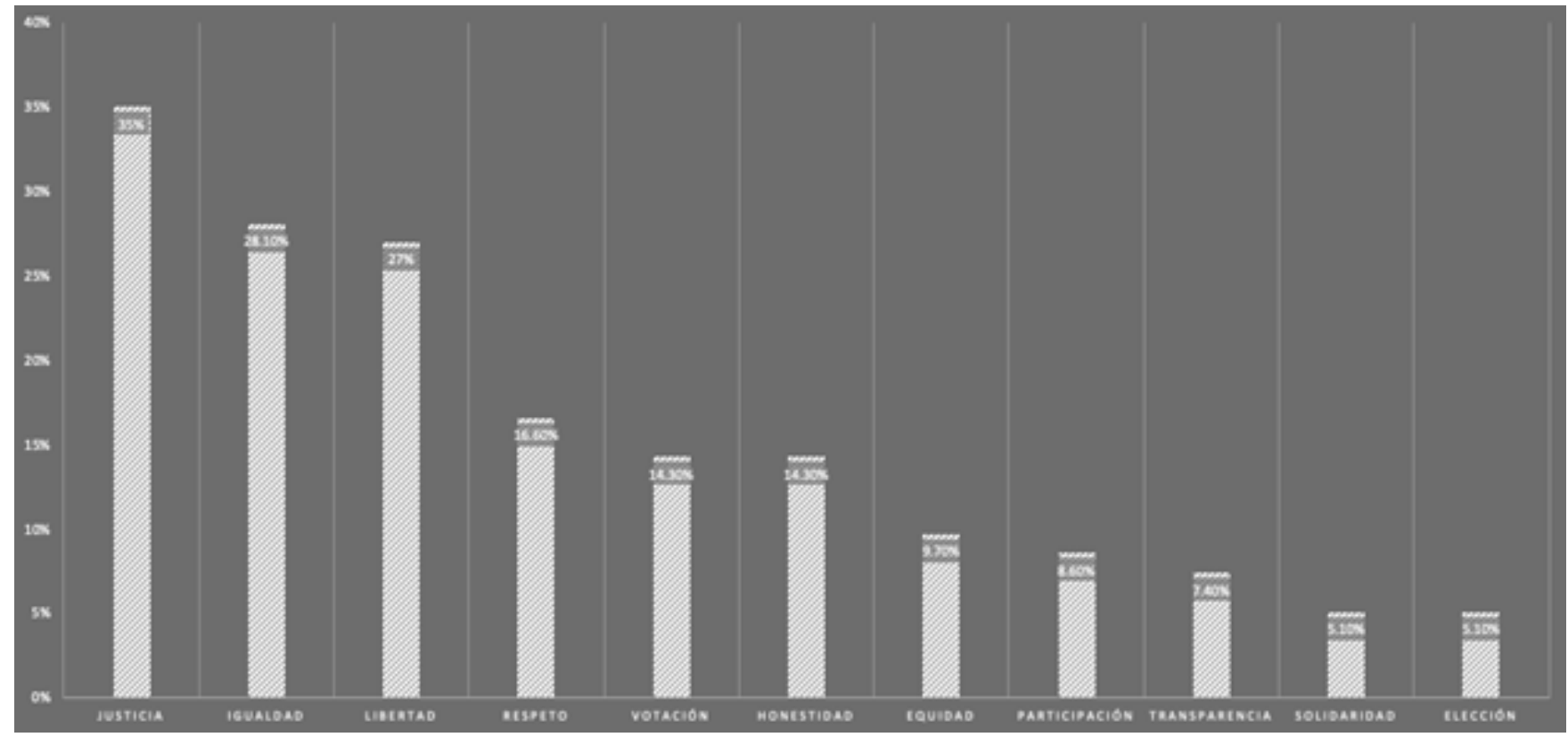

Figura 2. Principios de la democracia mencionados por el estudiantado con su respectivo porcentaje de respuesta.

Fuente: Elaboración propia.

donaciones para apoyar a las víctimas de un desastre (51.8\%), en último lugar se encuentra el pintar paredes $(3.2 \%)$.

A los estudiantes los motiva a participar en una actividad política el que sirva como protesta por alguna injusticia (68.6\%), el 59.1\% manifestó que los motiva cuando se obtiene algún beneficio, $54.1 \%$ los motiva el que los padres se los soliciten, al $48.3 \%$ los motivaría que sus amistades participaran, y $43.8 \%$ el considerarlo una obligación. Hay cierto grado de involucramiento con las problemáticas de extensión social. Esto indica que tienen conocimiento de esos mecanismos y hay una disposición a utilizarlos en caso de ser necesario.

Un ciudadano interesado en lo que sucede en su comunidad, los jóvenes estudiantes señalaron que se informan sobre lo que sucede en el país por medio de Facebook, Twitter y/o Instagram (94.7\%), la televisión $(70.2 \%)$, y accediendo a reportajes digitales (58\%); el resto de los recursos utilizados se encuentra en la Figura 3.

Estudios como el de Saldierna, Marañón y Muñoz (2015) coinciden en que el consumo primordial de información se realiza a través de redes sociales digitales, aspecto característico de las nuevas generaciones y su integración del uso de Internet de forma ubicua. Sin embargo, la televisión sigue estando presente previo a utilizar reportajes o

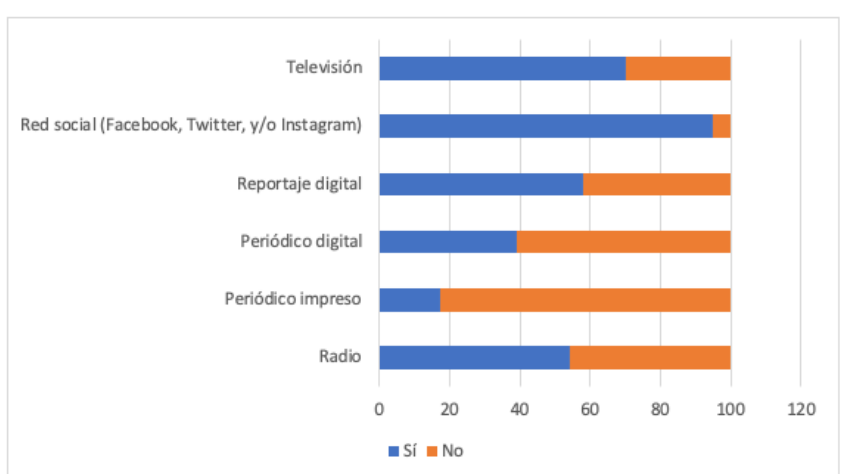

Figura 3. Porcentaje de estudiantes que manifestaron utilizar diversos medios de comunicación

Nota: $\mathrm{N}=480$.

Fuente: Elaboración propia.

periódicos digitales. La televisión es una herramienta de control mediático y una fuente de antivalores (Latapí, 2003), por lo cual es necesario que estos pre-ciudadanos desarrollen el pensamiento crítico y cuestionen la información que consumen.

Las actitudes fueron recabadas a partir de situaciones que parten de la opinión que tienen de la democracia en el país. A través de la presentación de la frase: Estoy desencantado (a) con la democracia en México, ellos podían elegían la opción de respuesta que expresara mejor su sentir entre cuatro. El mayor porcentaje se coloca en la opción parcialmente de acuerdo 40.3\%, seguido por totalmente de acuerdo $33.3 \%$, las otras dos opciones, 
colocadas en sentido opuesto como parcialmente en desacuerdo y totalmente en desacuerdo, obtuvieron el mismo porcentaje $13.2 \%$ cada una. Este resultado refleja que la mayoría (73.6\%) percibe una situación desalentadora respecto a la forma en que se conduce la democracia en México. Mientras que la frase No me interesa la política presentó una distribución similar entre las opciones totalmente de acuerdo (21.6\%), parcialmente de acuerdo (29.6\%), parcialmente en desacuerdo $(23.9 \%)$ y totalmente en desacuerdo $(24.9 \%)$. Respecto a la política, los estudiantes tienen una postura de interés polarizada.

$\mathrm{Al}$ conjugar que hay un aspecto cognitivo basado en un constructo sobre democracia y como funciona, y un sentimiento negativo hacia esta e incluso hacia la política que parece sobrepasar el conocimiento de los sujetos, no se asimila el involucrarse en actividades políticas como una obligación para la construcción de la democracia, indica que, en términos de cultura política democrática, se asemeja a una cultura de subordinación, comportamiento no deseable en la formación ciudadana.

Los valores identificados durante la revisión de los módulos de aprendizaje, o libros de texto, con los que trabajaban los estudiantes que conformaron la muestra, son: amistad, fraternidad, honestidad, igualdad, justicia, libertad, respeto, responsabilidad, solidaridad y tolerancia. Este listado se les proporcionó a los jóvenes, se les solicitó que seleccionaran los tres más relevantes y los colocaran en orden de importancia.

En primer lugar, se encuentra el respeto (44.4\%), seguido de la honestidad (15.9\%), y en tercer lugar ubicaron la libertad (15.7\%). Este último concuerda con los valores de la democracia y los derechos humanos, pero es menos relevante para los jóvenes estudiantes. Los otros valores que nos hablan sobre el bienestar del colectivo son la igualdad y la fraternidad; esteúltimo no recibió ninguna mención. Sin embargo, su elección denota una prevalencia del discurso formal que se encuentra en los materiales, en donde se menciona el respeto primordialmente, y dificulta el reconocer si en verdad es un valor que se lleva a la practica en la cotidianeidad o bien, una reproducción del discurso escolar. No se indagó sobre el constructo individual de los estudiantes respecto a los valores seleccionados, ese es un tema que queda pendiente.

La democracia se lleva a cabo de forma concreta a través de la ciudadanía, para esto es necesario que se tenga una construcción de la organización social, que conforme lo manifestaron los jóvenes, el colectivo prevalece sobre lo individual, además se deben respetar los derechos y tener unidad con las leyes vigentes (Touraine, 2000). Estos aspectos se retoman desde el estado de derecho.

\subsection{Estado de derecho}

Con relación al estado de derecho, conocimiento de la Ley General de los Derechos de Niñas, Niños y Adolescentes, en la que se ubica la media de edad de la población, llama la atención la falta de reconocimiento a dos derechos, el ser prioridad, al ser sujetos menores de edad y migrar, ya que las respuestas estaban divididas.

En la Tabla 2 se muestran todos los resultados obtenidos. Se visualiza en los cambios de tendencia, aquellosítemsque no son derechosy fueron incluidos a modo de control, estos son el ser discriminado, ausentarme de la escuela, profesar por imposición una religión y revisión de tus pertenencias por parte de la autoridad.

Sobre el conocimiento de la legislación en México respecto a los derechos a la educación, salud y trabajo se encontró que $70.2 \%$ lo identificó el artículo 3ro. relativo a la educación; en contraste con el derecho a la salud contenido en el artículo 4to identificado solo por $41 \%$. El artículo 123 que aloja el derecho al trabajo digno fue identificado por 70.4\%. Es importante en este caso retomar el conocimiento que tienen y agregar en las políticas educativas, los artículos, las instituciones y los medios a través de los cuales los jóvenes pueden acceder a tales derechos, para requerir su cumplimiento, o la exigencia de estos.

Por otro lado, también identificaron los derechos a ser adquiridos como ciudadanos mexicanos. Los estudiantes lograron identificar el tener acta de nacimiento (71.4\%), obtener información de lo que pasa en el contexto social a través de diversos medios (78.1\%), analizar la información que se obtiene de diversos medios y solicitar ampliación o aclaración de ésta (81.5\%), respetar a las personas con condiciones de desigualdad social; que tengan creencias religiosas, orientaciones sexuales, ideologías políticas o costumbres con $84.5 \%$, y tener un juicio justo e imparcial con $87.7 \%$; pero no ser representante de casilla durante las elecciones (49.1 $\%)$. 
Tabla 2. Porcentaje de estudiantes que identificaron derechos contenidos en la Ley General de niñas, niños y adolescentes

\begin{tabular}{lcc}
\hline Nombre del derecho & Es derecho & $\begin{array}{c}\text { No es } \\
\text { derecho }\end{array}$ \\
\hline Vida, supervivencia y desarrollo & 94.5 & 5.5 \\
\hline Ser prioridad & 30.3 & 69.7 \\
\hline Tener una identidad & 96.4 & 3.6 \\
\hline Vivir en familia & 86.9 & 13.2 \\
\hline $\begin{array}{l}\text { Ejercer y defender mis derechos } \\
\text { universales }\end{array}$ & 96.9 & 3.1 \\
\hline $\begin{array}{l}\text { Vivir en condiciones de bienestar y a } \\
\text { un sano desarrollo integral }\end{array}$ & 97.7 & 2.3 \\
\hline $\begin{array}{l}\text { Vivir una vida libre de violencia y a la } \\
\text { integridad personal }\end{array}$ & 97.3 & 2.7 \\
\hline $\begin{array}{l}\text { Protección de la salud y a la } \\
\text { seguridad social }\end{array}$ & 99.0 & 1.0 \\
\hline $\begin{array}{l}\text { Inclusión de niñas, niños y } \\
\text { adolescentes con discapacidad }\end{array}$ & 86.5 & 13.5 \\
\hline Descanso y esparcimiento & & \\
\hline $\begin{array}{l}\text { Libertad de expresión y de acceso a } \\
\text { la información }\end{array}$ & 97.7 & 24.8 \\
\hline Participación & & 2.3 \\
\hline Asociación y reunión & 93.1 & 6.9 \\
\hline Intimidad & 84.8 & 15.2 \\
\hline Migrar & 78.7 & 21.3 \\
\hline $\begin{array}{l}\text { Acceso a las Tecnologías de la } \\
\text { Información y Comunicación }\end{array}$ & 50.6 & 49.4 \\
\hline Nota: Sereportan los porcentes & \\
\hline
\end{tabular}

Nota: Se reportan los porcentajes válidos. $\mathrm{N}=480$.

Fuente: Elaboración propia

Cuando los sujetos se comportan dentro de los limites del estado de derecho, nos referimos a una cultura de la legalidad, sobre ésta se inquirió sobre actividades legales o ilegales en el Estado de Sonora, se obtuvieron los resultados reportados en la Tabla 3.

En su mayoría los jóvenes lograron diferenciar las actividades legales. Es importante señalar que el único ítem que muestra una respuesta errónea alta es Los matrimonios entre personas del mismo sexo, acorde con la legislación vigente para este estado es ilegal, aun cuando se han aprobado leyes legalizando el matrimonio igualitario en otros estados. Si se analiza desde las características propias de la generación, Twenge (2017) menciona que los jóvenes aceptan y ven el matrimonio igualitario como algo común, y como un derecho para las minorías de orientación sexualmente diversa. En este caso la repuesta denota una tensión y un posible desconocimiento entre lo que está establecido jurídicamente y lo que ellos consideran debería de estar garantizado por la ley.

Tabla 3. Porcentaje de estudiantes que identificaron las actividades legales e ilegales para el estado de Sonora

\begin{tabular}{|c|c|c|}
\hline Actividades legales e ilegales & Legal & Ilegal \\
\hline Beber en la vía pública & 8.9 & 91.1 \\
\hline Sobornar o dar mordida & 3.4 & 96.6 \\
\hline Abortar & $9 \cdot 3$ & 90.7 \\
\hline Grafitear & 5.6 & $94 \cdot 4$ \\
\hline $\begin{array}{l}\text { Los matrimonios entre personas del } \\
\text { mismo sexo }\end{array}$ & 45.0 & 55.0 \\
\hline Pagar impuestos por tener una vivienda & 90.4 & 9.6 \\
\hline Comprar algo sabiendo que es robado & 10.1 & 89.9 \\
\hline $\begin{array}{l}\text { Que los padres peguen a los hijos para } \\
\text { corregirlos }\end{array}$ & 36.1 & 63.9 \\
\hline Fumar marihuana & 8.8 & 91.2 \\
\hline $\begin{array}{l}\text { Consumir drogas "fuertes" (cocaína, } \\
\text { anfetaminas, etc.) }\end{array}$ & 2.1 & $97 \cdot 9$ \\
\hline Tirar basura en lugares públicos & 19.1 & 80.9 \\
\hline Comprar antibióticos con receta médica & 91.9 & 8.1 \\
\hline Manejar en estado de ebriedad & 1.7 & 98.3 \\
\hline $\begin{array}{l}\text { Superar los límites de velocidad } \\
\text { establecidos }\end{array}$ & 1.5 & 98.5 \\
\hline Poner un diablito (tomar electricidad) & 2.3 & $97 \cdot 7$ \\
\hline $\begin{array}{l}\text { Colgarse del Internet o de la señal de } \\
\text { cable }\end{array}$ & 13.0 & 87.0 \\
\hline Manejar un vehículo con licencia & 97.1 & 2.9 \\
\hline
\end{tabular}

Fuente: Elaboración propia.

Nota: Las negritas indican la respuesta correcta.

No siempre corresponde el estado de derecho de una comunidad con lo que se desea o se considera correcto (Díaz, 1998). De manera similar sucede con el que los padres les peguen a los hijos, dado que la violencia y el castigo físico son ilegales, las respuestas de más de un tercio de los informantes de que es legal pueden denotar una aceptación cultural.

En el listado de comportamientos legales e ilegales que los estudiantes identificaron realizar, destacan el que los jóvenes hayan tomado bebidas alcohólicas en casa, seguido de conducido un vehículo de motor sin licencia, y el participar en una pelea donde haya habido golpes. De forma contraria, las primeras tres actividades que negaron realizar son vendido un artículo robado o de procedencia dudosa; consumido otra droga, diferente a la marihuana; y comprado un artículo robado. El resto de los resultados se puede observar en la Tabla 4. 
Tabla 4. Resultados de comportamientos incorrectos y/o ilegales que los jóvenes manifiestan haber realizado, en porcentaje

\begin{tabular}{|c|c|c|}
\hline Comportamientos & Sí & No \\
\hline $\begin{array}{l}\text { Tomado bebidas alcohólicas (cerveza, tequila, } \\
\text { etc.) en casa. }\end{array}$ & 41.5 & 58.5 \\
\hline $\begin{array}{l}\text { Tomado bebidas alcohólicas en lugares públicos } \\
\text { (Por ejemplo: parques, playas, entre otros.) }\end{array}$ & 29.6 & 70.4 \\
\hline Fumado marihuana. & 10.6 & 89.4 \\
\hline Consumido otra droga, diferente a la marihuana. & 6.7 & $93 \cdot 3$ \\
\hline Tomado dinero de tus padres sin permiso. & 24.6 & $75 \cdot 4$ \\
\hline Utilizado una identificación falsa. & $9 \cdot 4$ & 90.6 \\
\hline $\begin{array}{l}\text { Dado dinero a un funcionario público a cambio } \\
\text { de un favor u omisión a una falta/multa } \\
\text { administrativa (Policías, maestros, guardias u } \\
\text { otros). }\end{array}$ & 8.4 & 91.6 \\
\hline $\begin{array}{l}\text { Consumido alimentos sin pagar en un } \\
\text { establecimiento comercial. }\end{array}$ & 9.2 & 90.6 \\
\hline $\begin{array}{l}\text { Conducido un vehículo de motor sin licencia de } \\
\text { automovilista. }\end{array}$ & 40.4 & 59.6 \\
\hline Amenazado verbalmente a otra persona. & 42.9 & 57.1 \\
\hline $\begin{array}{l}\text { Participado en una pelea donde haya habido } \\
\text { golpes. }\end{array}$ & 33 & 67 \\
\hline $\begin{array}{l}\text { Compartido o publicado imágenes y/o } \\
\text { videos en Internet de otras personas sin su } \\
\text { consentimiento. }\end{array}$ & 25.8 & 74.2 \\
\hline Comprado un artículo robado. & 8.2 & 91.8 \\
\hline $\begin{array}{l}\text { Vendido un artículo robado o de procedencia } \\
\text { dudosa. }\end{array}$ & 3.4 & 96.6 \\
\hline Pegado a un joven menor que tú. & 23.7 & 76.3 \\
\hline $\begin{array}{l}\text { Burlado de alguien por tener alguna diferencia } \\
\text { física, su vestimenta, o hablar en otro idioma }\end{array}$ & 28.2 & 71.8 \\
\hline
\end{tabular}

Nota: $\mathrm{N}=480$.

Fuente: Elaboración propia.

Al respecto, el optar por realizar una actividad legal o ilegal es un ejercicio de la libertad, pero, al realizar una actividad ilegal, se contrapone con los valores de la democracia en donde la libertad debe ser utilizada para apegarse al estado de derecho (Salazar \& Woldenberg, 2012; Sartori, 2012).

El aspecto relacionado con actitudes se visualiza con la propensión a realizar una denuncia al ser testigos de una actividad ilegal. Se les dio la situación: si un joven estudiante se encuentra en compañía de sus amistades en una tienda comercial, y uno de ellos roba un artículo, ¿qué harían? los informantes mencionaron que le solicitarían a que regresara a pagarlo, si la persona nos les hace caso, ya no actúan, siguen su camino $(58.7 \%)$, casi un tercio
(28.9\%) además de decirle, lo reportaría con una autoridad competente, mientras que $10.3 \%$ ignoraría el comportamiento, y $\mathbf{2 . 1} \%$ lo reportaría sin decirle nada directamente.

Con base en los hallazgos, se deduce que no hay un compromiso ciudadano fuerte con el estado de derecho, al exigir que se cumpla la ley o bien que se respete el derecho del otro a quien le están usurpando. Aun cuando, en la sección de conocimiento identifican que lo legal es conducir con la licencia correspondiente, muchos jóvenes no lo hacen. Estas actividades ilegales realizadas muestran fallas en la autorregulación de los jóvenes, aspecto importante para la interacción pacifica según Marco (2003) y Chaux (2005), sin embargo, queda en duda si son comportamientos de orden social aceptados (Laveaga, 200o), que en lugar de excluir a quienes realizan acciones fuera del estado de derecho, les permiten incluirse en grupos sociales y/o una búsqueda de aceptación por lo pares (Bauman y Leoncini, 2018), o estar en un proceso de desarrollo de la madurez donde desafían a las autoridades.

\subsection{Propuesta para una escuela democrática}

Las respuestas que ofrecieron las y los jóvenes al solicitarles propuestas para impulsar una escuela democrática se pueden agrupar en las siguientes categorías : a) Aspectos formales, la cual hace referencia a dialogar sobre cambios curriculares, de poder o jerárquicos, y a herramientas de evaluación del conocimiento; b) dinámicas escolares, esto engloba el participar en proponer y realizar actividades, campañas y/o propuestas; y, c) agentes, esta se relaciona con distintos actores educativos y cambios o aspectos en los que les gustaría injerir.

Algunas opiniones reflejan la necesidad de ser visibilizado o ser tomado en cuenta, por ejemplo, algunos solicitan un espacio donde puedan opinar libremente, o bien, se les considere en la toma de decisiones, sus opiniones, sus necesidades. La opinión de algún estudiante refleja claramente en este sentido: "me gustaría que nos tomaran más en cuenta cuando se trata de nuestra seguridad a algunas personas no se les facilita llegar por la lluvia, etc. "(Informante 501228).

Relacionados con el respeto de su identidad como jóvenes hicieron referencia al querer participar en la definición de las políticas incluidas en el reglamento escolar vigente, en la planeación de eventos sociales 
y deportivos en donde ellos manifiestan ser receptores de actividades impuestas por los adultos (docentes y administrativos), incluso en participar para mejorar la limpieza y vigilancia de la escuela.

Entre las reglas de convivencia que mencionan querer impulsar en el plantel, está el discutir el uso del uniforme, usar el cabello largo sobre todo en hombres, el querer tener voz, y realizar campañas de inclusión. Esto a su vez, denota que en la institución hay rasgos de autoritarismo lo cual coarta la libre expresión de los jóvenes. Al respecto, una opinión expresó: "que la opinión de los alumnos sea realmente tomada en cuenta y que respeten nuestra identidad" (Informante 502103).

Pocos jóvenes hicieron referencia a cuestiones de mejoramiento académico, sin embargo, se encuentran peticiones de elegir a sus docentes, tener maestros de calidad, la integración de la comunidad escolar (incluyendo administrativos, intendentes e incluso padres de familia), el poder dar retroalimentación sobre el desempeño de los maestros y el contar con un buzón de quejas.

De igual manera los jóvenes critican los comportamientos y actitudes de algunos de sus compañeros, "primero, ocupamos que los estudiantes sean mejores personas, así que iniciamos mejorándoles de manera moral, luego los impulsaríamos a participar" (Informante 501201), mientras que el informante 502145 opinó: "creería que ejerceríamos mejor presión si cambiamos la mentalidad de los alumnos en que poseen la habilidad de modificar la condición donde se encuentren"

Estas opiniones reflejan de manera preponderante que el bachillerato presenta un ambiente de autoritarismo donde no se permite la libre expresión de los estudiantes, las acciones son tomadas por los directivos y a veces los profesores y no consideran aspectos como la libertad, su identidad, ni formas de organización representativa al interior de la escuela, afirmaciones encontradas en Ortiz (2014) y en el informe de la OEI (2017). Conjuntamente, RaveloMedina y Radovic-Sendra (2016) mencionan que los estudiantes tienen la disposición para participar, pero que la estructura escolar no se los permite; sus hallazgos son similares a los de esta investigación y a los expuestos por Razo (2018). Esta experiencia escolar puede desarrollar al ciudadano activo o pasivo (Dehdar, Sayegani, Arbab, Arzhandeh, Roshanray, Raeisi \& Kuhi, 2019). En tanto que, para fomentar el desarrollo del ciudadano activo, como lo menciona el objetivo de la Educación Media Superior, es necesario facilitar el protagonismo estudiantil permitiendo que los jóvenes tomen decisiones que permitan la práctica plena de sus derechos (Martínez, 2005).

Se sobreentiende que las instituciones educativas de educación media superior son evaluadas por organismos internacionales y nacionales, y que tienen logros de aprendizaje que cumplir. Además de que las partidas presupuestales dependen en parte de los logros alcanzados. La misma premura del sistema genera una visión a corto plazo en los docentes y administrativos que ocasiona que se enfoquen en cumplir con impartir los contenidos del ciclo y evaluarlos, siendo que la formación en ciudadanía es un objetivo a largo plazo que no tendrá frutos tan concretos como lo es una calificación aprobatoria, el acceso a una beca o proyecto, pero que coadyuvará a reconstruir el tejido social, a disminuir la violencia y fomentar una cultura de paz, y a fortalecer la democracia con la participación de ciudadanos informados, críticos e interesados en el bien común.

\section{Conclusiones e implicaciones en la formación de ciudadanía en los jóvenes}

En términos sociales, los jóvenes estudiantes cuentan con competencias ciudadanas democráticas orientadas hacia el estado de derecho, en pro del bienestar del colectivo. Sin embargo, denotan que el ambiente educativo constriñe sus intenciones de participar e incluso limita su libre expresión, toma de decisiones y mostrar aspectos de su identidad personal. Este espacio escolar en vez de configurarse como una esfera pública de participación está replicando modelos jerárquicos restrictivos con participación limitada que puede generar la reproducción de comportamientos ciudadanos pasivos.

En tanto que algunas implicaciones económicas y sociales se dan en torno al desconocimiento de los derechos como lo es preservar la salud, el trabajo, y el migrar. Esto los podría colocar en una situación de vulnerabilidad al ingresar al ámbito laboral por no exigir tales derechos de su empleador. Asimismo, es necesario fortalecer la autorregulación en pro de la toma de decisiones legales, para evitar la toma de 
decisiones ilícitas que puedan dañar al sujeto y a la sociedad, como podría ser el aceptar sobornos y el robo hormiga. En la misma lógica, las competencias ciudadanas pueden aumentar la empleabilidad de los jóvenes.

El que los ciudadanos exijan a los representantes políticos, a las instituciones el cumplimiento de funciones es primordial para mantener y fortalecer la democracia. Como consecuencia de la pandemia, la mayoría de las dependencias públicas tienen cuentas oficiales a los cuales ellos podrían acceder a realizar consultas, o, si es el caso, a realizar una queja o incluso una demanda.

Si bien los jóvenes priorizan socializar en entornos digitales dado la ubicuidad de la tecnología, también se puede extender la formación ciudadana hacia esos espacios promoviendo la interacción en foros de discusión, grupos de debate u otros. Así como proveerlos de habilidades mediáticas e informacionales con pensamiento crítico que los ayude a detectar casos de acoso cibernético y mantenerse a salvo dentro de estos entornos. También lo pueden hacer en espacios públicos, y pueden exigir y demandar que tales espacios de intercambio existan para ellos.

Es importante extender esta investigación a maestros y administrativos para determinar si en realidad están capacitados para generar un escenario democrático en la escuela y dentro del aula. Si bien es cierto que las imposiciones a nivel federal son determinantes, hay una libertad de cátedra y de gestión limitada que puede ser aprovechada para dicha finalidad.

Retomando la idea de Heater (2007) de que la formación para la ciudadanía debe atender al dilema de la actualidad, se tiene que trazar una ruta crítica respecto a donde dirigir el plan educativo respecto a los conocimientos que el ahora pre-ciudadano requiere para fungir con su rol de ciudadano activo, como por ejemplo, el conocer las nuevas instancias y procedimientos para exigir sus derechos como lo es la Comisión de Derechos Humanos, y el Instituto Mexicano de la Juventud donde pueden acceder a proyectos y convocatorias que les permitan colaborar, recibir cursos de formación sobre empleo, salud y participación social. Asimismo, desarrollar comportamientos, actitudes y valores que sobrepasen su valoración afectiva, es decir que se comporten de manera consciente hacia el bien común y no actúen guiados por las emociones y dañen a otros.
Asimismo, reforzar la empatía y la tolerancia, tratar temas como la modificación de los lenguajes para dar paso al lenguaje incluyente, como es el uso del sufijo -e como género neutro en le español.

Una propuesta para completar esta investigación hace referencia al estudio de la participación no convencional, retomando las nociones de ContrerasIbáñez, Correa y García y Barragán (2005), es necesario indagar la voz de los adolescentes, que hacen y como ejercen formas de democracia fuera de la escuela, dar la oportunidad a los adolescentes de involucrarse en ejercicios democráticos. Por ello se recomienda realizar un estudio experimental que implemente un programa de formación de ciudadanía democrática activa, y permita medir los efectos sobre los comportamientos y actitudes de los jóvenes.

\section{Referencias bibliográficas}

Aragón, A. (2015). Ciudadanía. La lucha por la inclusión y los derechos. Gedisa.

Arango, X., Leyva, O., Marañón, F., \& Lozano, D. (Coords). (2017). Cultura de la legalidad ciudadana. Análisis sobre el caso de Monterrey. Editorial Fontamara.

Asociación Mexicana de Agencias de Investigación de Mercado (2018). Niveles Socio Económicos. [Página Web]. https://bit.ly/2OZUoXy

Astiz, M. (2007). Reflexiones sobre la educación para la ciudadanía en la República Argentina. Una perspectiva comparada. Revista Iberoamericana sobre Calidad, Eficacia y Cambio en Educación, 32-50. http://www. redalyc.org/articulo.oa?id=55140503

Ávila, I. \& Díaz, O. (2017). Algunas actitudes de los jóvenes hacia la política: ¿compromiso cívico o desafección política? En S. Gómez Tagle (Coord.). La Cultura Política de los Jóvenes, 409-443. Colegio de México.

Bolívar, A. (2016). Repensar la inclusión social desde la educación: algunas experiencias en América Latina. Revista Internacional de Educación para la Justicia Social, 5, 177-194. https://doi.org/10.15366/riejs2016.5.1 Canto, M. (2002). Lo Cívico en lo Público. Estrategias y herramientas de incidencia ciudadana en políticas públicas. Centro de Estudios Sociales y Culturales Antonio de Montesinos, A.C.

Caro, M., Pivatto, D., Quinteros, L., Sema, G., \& Torrejón, E. (2012). Conocimiento político en estudiantes secundarios. Revista Electrónica de Psicología Política, 9 (27), 81-95. 
Consejo para la Evaluación de la Educación del Tipo Medios Superior A.C. (2019). Listado de Planteles Miembros del PC-SINEMS. [archivo digital]. https:// bit.ly/2OHiKVL

Contreras-Ibáñez, C., Correa, F., \& García \& Barragán, L. (2005). Participación Política no convencional: culturas de protesta vs. culturas institucionales. Polis: Investigación y Análisis Sociopolítico y Psicosocial, 1(1), 181-210.

Dehdar M., Sayegani L., Arbab E., Arzhandeh M., Roshanray M., Raeisi A., \& Kuhi L. (2019). Role of schools in educating the active citizen. UCT Journal of Social Sciences and Humanities Research, 7(2), 31-36.

Dirección General del Bachillerato. (2017). Documento Base del Bachillerato General. Secretaría de Educación Pública. http://bit.ly/2N8ZZcp

Fernández, L. (2013). La educación ciudadana en el sistema educativo mexicano. Analéctica,o(1). https:// doi.org/10.5281/zenodo.3829889

Garay, J., Díaz-Loving, R., Frías, M., Limón, B., Lozano, I., Rocha, T., \& Zacarías, M. (2008). Intereses y valores en jóvenes mexicanos. Enseñanza e Investigación en Psicología, 13 (2), 201-2014.

Gómez, S., Tejera, H., Aguilar, J., Ramírez, J., \& Díaz, F. (2012). Informe de la Encuesta Nacional de Cultura Política de los Jóvenes 2012. El Colegio de México. https://bit.ly/37VkZw8

Heater, D. (2007). Ciudadanía. Una breve historia. Alianza Editorial.

Instituto Federal Electoral. (2013). Estudio Censal de la Participación en las Elecciones Federales de 2012. https://bit.ly/2OVxXkE

Instituto Nacional Electoral. (2016). Estudio Censal sobre la Participación Ciudadana en las Elecciones Federales de 2015. https://bit.ly/37X6OXu

Instituto Mexicano de la Juventud. (2012). Encuesta Nacional de Valores en Juventud 2012. https://bit. ly/33Fvodk

Latapí, (2003). El debate Sobre los Valores en la Escuela Mexicana. Fondo de Cultura Económica.

Marco, B. (2003). Educación para la ciudadanía. Un enfoque basado en el desarrollo de competencias transversales. Narcea.

Martínez, J. (2005). Educación para la ciudadanía. Morata.

Mejía, A., \& Perafán, B. (2006). Para acercarse al dragón, para amansarlo, es necesario haberlo amansado primero: una mirada crítica a las competencias ciudadanas. Revista de Estudios Sociales, 23, 23-35. http://bit.ly/36BhSZj

Moreno, S., \& Peniche, R. (2020). La formación en valores como reto para el docente de Educación
Media Superior en México. Dilemas Contemporáneos: Educación, Política y Valores, 7 (2).

Olivera, I. (2009). Juventud rural y lucha por la ciudadanía: límites y posibilidades en los procesos de socialización. Antropológica, 27 (27), 7-24.

Organización de Estados Iberoamericanos (2017). Miradas sobre la educación en Iberoamérica. Desarrollo profesional y liderazgo de directores escolares en Iberoamérica. Organización de Estados Iberoamericanos.

Ortiz, J. (2014). Democracia en la escuela: Comencemos con el derecho a la palabra. Signos filosóficos, 16(31), 97-124.

Ravelo-Medina, M., \& Radovic-Sendra, Y. (2016). Representaciones de lo político en estudiantes secundarios en Santiago de Chile: resignificando el sentido de la formación ciudadana. Revista Latinoamericana de Ciencias Sociales, Niñez $y$ Juventud, 16(1), 389-402. http://dx.doi. org/10.1160o/1692715x.16124

Razo, A. (2018). La reforma integral de la educación media superior en el aula: política, evidencia y propuestas. Perfiles Educativos, 11(159), 90-106. http:// bit.ly $/ 2 \mathrm{~T}_{7} \mathrm{PCtc}$

Ruiz, A., \& Chaux, E. (2005). La Formación de Competencias Ciudadanas. ASCOFADE.

Salazar, L., \& Woldenberg, J. (2020). Principios y valores de la democracia. Cuadernos de Divulgación de la Cultura Democrática. Instituto Nacional Electoral. https://www.ine.mx/wp-content/uploads/2021/o2/ CDCD-o1.pdf

Saldierna, A., Marañón, F., \& Muñíz, C. (2015). El papel de la comunicación en la generación de interés y conocimiento político entre los preciudadanos: aplicación del modelo O-S-R-O-R al caso mexicano. Revista Mexicana de Opinión Pública, 147-165.

Saldierna, A., Muñiz, C., \& Marañón, F. (2017). Formación ciudadana en la democracia mexicana: análisis del efecto de los medios de comunicación en la generación de conocimiento político en los pre-ciudadanos. ALCEU, 17 (34), 198-2015.

Sartori, G. (2012). ¿Qué es la democracia? Taurus.

Stake, R. (2004). Standards-Based \& Responsive Evaluation. SAGE Publications.

Taddei, I. (2019). Formación Ciudadana a través de la Participación Política Estudiantil en la Universidad de Sonora. [Unpublished masters dissertation]. Universidad de Sonora.

Toro, J. (2000). Principios básicos de la democracia. En Jahir Rodríguez... El Presupuesto Participativo: Defendiendo lo público y construyendo ciudadanía. La experiencia del departamento de Risaralda. 
Colombia. Gobernación de Risaralda, 136 - 148. United Nations Educational, Scientific, and Cultural Secretaría de Planeación Departamental. https:// www.eumed.net/libros-gratis/2007a/234/28.htm

Touraine, A. (2000). ¿Qué es la democracia? Fondo de Cultura Económica.

Twenge, J. (2017). iGen. Why Today's Super-Connected Kids Are Growing Up Less Rebellious, More Tolerant, Less Happy and Completely Unprepared for Adulthood. Atria Books.

Organization. (1948). Declaración Universal de Derechos Humanos. http://portal.unesco. org/es/ev.php-URL_ID=26053\&URL_DO=DO_ TOPIC\&URL_SECTION=201.html

Weiss, E., Guerra, I., Guerrero, E., González, J., Grijalva, O., \& Ávalos, J. (2008). Young people and high school in Mexico: subjectivisation, others and reflexivity. Ethnography and Education, 3(1), 17-31. https://doi. org/10.1080/17457820801899025 